\title{
Antihyperlipidemic Effects of Rhapontin and Rhapontigenin from Rheum undulatum in Rats Fed a High-Cholesterol Diet
}

Authors

Affiliations
Sung-Pil Jo ${ }^{1}$, Jeong-Keun Kim² , Young-Hee Lim ${ }^{1,3}$

${ }^{1}$ Department of Public Health Science (BK21 PLUS Program), Graduate School, Korea University, Seoul, Republic of Korea

${ }^{2}$ Department of Chemical Engineering and Biotechnology, Korea Polytechnic University, Shihung-si, Gyeonggi-do, Republic

of Korea

${ }^{3}$ Department of Laboratory Medicine, Korea University Guro Hospital, Seoul, Republic of Korea
Key words

- Rheum undulatum

- Polygonaceae

- methoxylated stilbene

- antihyperlipidemic effect

๑ high-cholesterol diet received April 8, 2014

revised July 21,2014

accepted July 29, 2014

\section{Bibliography}

Dol http://dx.doi.org/ 10.1055/s-0034-1382999

Published online August 15, 2014

Planta Med 2014; 80: 1067-1071 @ Georg Thieme Verlag KG Stuttgart · New York ISSN 0032-0943

Correspondence

Prof. Young-Hee Lim

Department of Public Health Science (BK21 PLUS Program)

Graduate School

Korea University

Seongbuk-gu

Seoul 136-703

Republic of Korea

Phone: + 8229402815

Fax: +8229402819

yhlim@korea.ac.kr

\section{Abstract}

$\nabla$

Rhapontin was purified from a methanol extract from the roots of Rheum undulatum, and rhapontigenin was produced by an enzymatic transformation of rhapontin. Rats were fed a high-cholesterol diet to induce hyperlipidemia, followed by oral treatment with rhapontin or rhapontigenin (1-5 mg/kg/day). Rhapontin and rhapontigenin treatment resulted in a significant $(p<0.05)$ dose-dependent decrease in the serum lipid level, while the high-density lipoprotein cholesterol level increased slightly compared with the experimental control. Furthermore, rhapontin and rhapontigenin treatment improved the pathological characteristics of the degenerating fatty liver in high-cholesterol diet-induced hyperlipidemic rats dose-dependently. Aspartate aminotransferase and alanine aminotransferase levels in rhapontin- and rhapontigenin-treated hyperlipidemic rats were not significantly different from those in the control. These results indicate that

\section{Introduction}

$\nabla$

Hyperlipidemia, an increase in the blood lipid lev$\mathrm{el}$, is the leading cause of cardiovascular disease and death worldwide. Reducing the LDL-C level in individuals with hyperlipidemia decreases the risk of cardiovascular disease [1]. By contrast, HDL-C lowers the risk of cardiovascular diseases by reversing cholesterol transport, inhibiting LDL-C oxidation, and decreasing platelet aggregability [2,3]. Statins are widely prescribed as lipid lowering agents; however, they can elicit serious side effects such as myopathy and hepatocytotoxicity $[4,5]$. Therefore, the development of new agents for lowering blood lipid levels is needed.

Stilbenes are well-studied compounds that possess anticancer, antioxidative, and anti-inflammatory activities [6-8], and methoxylated stil- rhapontin and rhapontigenin can be used as potent antihyperlipidemic agents.

\section{Abbreviations \\ $\nabla$ \\ ALT: $\quad$ alanine aminotransferase \\ AST: $\quad$ aspartate aminotransferase \\ HCD: high-cholesterol diet \\ HDL-C: high-density lipoprotein cholesterol \\ HE: hematoxylin and eosin \\ LDL-C: low-density lipoprotein cholesterol \\ RHA: rhapontin \\ RHG: rhapontigenin \\ TC: $\quad$ total cholesterol \\ TG: triglyceride \\ VLDL-C: very low-density lipoprotein cholesterol}

Supporting information available online at http://www.thieme-connect.de/products

benes enhance those bioactivities [9,10]. Rhapontigenin (3,3',5-trihydroxy-4'-methoxystilbene) is an aglycone of rhapontin (3,3',5-trihydroxy-4'methoxystilbene-3-O-glucoside), which is isolated from the roots of Rheum undulatum $\mathrm{L}$. from the family Polygonaceae ( Fig. 1) [11]. Rhapontigenin is a methoxylated stilbene with anticancer, antioxidative, and anti-inflammatory effects [12, 13]. Rhapontigenin is much more potent than rhapontin in inhibiting thrombosis and allergic reactions [14]. To increase the bioactivity of rhapontin isolated from a methanol extract from the roots of Rheum undulatum $[15,16]$, rhapontigenin is prepared from rhapontin by an enzymatic transformation [17]. In this study, RHA and RHG were investigated for their antihyperlipidemic activity, and the results were compared with simvastatin, a well-known hypolipidemic drug. 


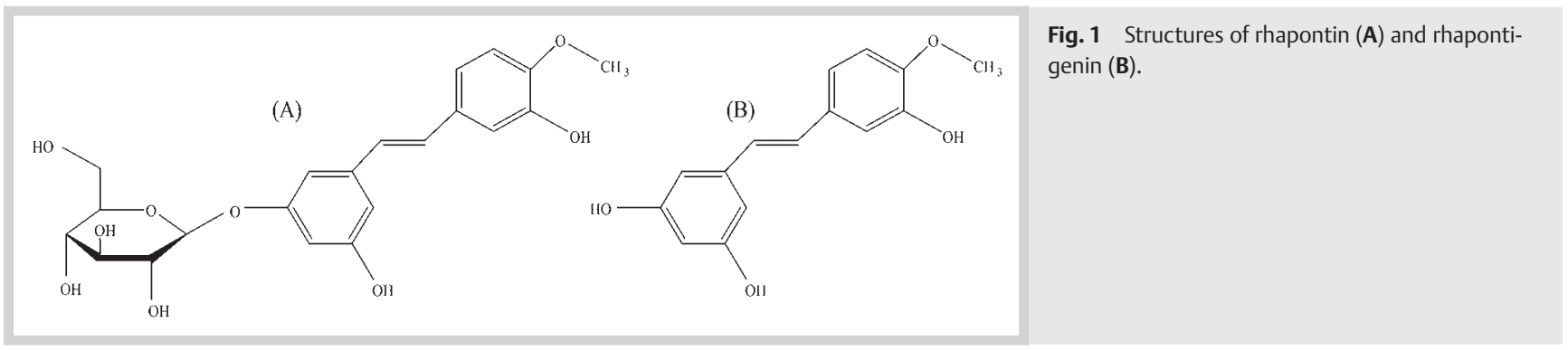

\begin{tabular}{|c|c|c|c|}
\hline Treatment group & $\% \Delta$ Weight on day 28 & Relative liver weight & $\begin{array}{l}\text { Average daily diet } \\
\text { consumption (g/day) }\end{array}$ \\
\hline I & $141.7 \pm 14.5^{a, b}$ & $2.8 \pm 0.3^{a}$ & $15.3 \pm 1.4$ \\
\hline II & $155.8 \pm 17.0^{\mathrm{b}}$ & $4.4 \pm 0.8^{c, d}$ & $15.9 \pm 2.9$ \\
\hline III & $147.4 \pm 14.8^{\mathrm{a}, \mathrm{b}}$ & $4.0 \pm 0.7^{d}$ & $15.5 \pm 2.6$ \\
\hline IV & $143.4 \pm 10.7^{\mathrm{a}, \mathrm{b}}$ & $3.7 \pm 0.3^{b, c, d}$ & $17.2 \pm 3.1$ \\
\hline V & $148.8 \pm 9.3^{\mathrm{a}, \mathrm{b}}$ & $4.2 \pm 0.4^{b, c, d}$ & $16.0 \pm 2.8$ \\
\hline VI & $143.4 \pm 12.0^{\mathrm{a}, \mathrm{b}}$ & $4.1 \pm 0.4^{c, d}$ & $17.2 \pm 2.5$ \\
\hline VII & $137.9 \pm 6.5^{\mathrm{a}, \mathrm{b}}$ & $3.9 \pm 0.4^{b, c}$ & $15.7 \pm 2.7$ \\
\hline VIII & $143.1 \pm 21.1^{\mathrm{a}, \mathrm{b}}$ & $3.5 \pm 0.3^{b}$ & $16.5 \pm 2.8$ \\
\hline IX & $130.5 \pm 7.5^{a}$ & $3.9 \pm 0.6^{b, c, d}$ & $16.5 \pm 2.1$ \\
\hline
\end{tabular}

Table 1 Effects of the high-cholesterol diet and simvastatin, rhapontin, or rhapontigenin treatment on body weight, relative liver weight, and average daily food consumption in rats.

Group I, normal diet + $10 \mathrm{~mL} / \mathrm{kg} /$ day distilled water; group II, HCD; group III, HCD $+1 \mathrm{mg} / \mathrm{kg} /$ day simvastatin; group IV, HCD + $1 \mathrm{mg} / \mathrm{kg} /$ day RHA; group V, HCD + $2.5 \mathrm{mg} / \mathrm{kg} /$ day RHA; group VI, HCD + $5 \mathrm{mg} / \mathrm{kg} /$ day RHA; group VII, HCD + $1 \mathrm{mg} / \mathrm{kg} /$ day RHG; group VIII, HCD $+2.5 \mathrm{mg} / \mathrm{kg} /$ day RHG; and group IX, HCD + $5 \mathrm{mg} / \mathrm{kg} /$ day RHG; a, b, c, d Means in the same column not sharing a common superscript are significantly $(\mathrm{p}<0.05)$ different between groups

\section{Results and Discussion \\ $\nabla$}

RHA, RHG, or simvastatin (positive control) was orally administered to HCD-fed rats for four weeks (Table 1S, Supporting Information). The percent changes ( $\% \Delta$ ) in body weight were not significantly reduced except in HCD-fed rats treated with RHG at $5 \mathrm{mg} / \mathrm{kg} /$ day ( $($ Table 1 ). The $\% \Delta$ body weight significantly $(\mathrm{p}<0.05)$ decreased in HCD-fed rats treated with RHG at $5 \mathrm{mg} /$ $\mathrm{kg} /$ day compared with the HCD-fed control. The relative liver weight increased in HCD-fed rats compared with the water-treated control; however, it decreased in HCD-fed rats treated with RHA and RHG compared with rats fed the normal diet. Daily food consumption was similar in all groups, indicating that the test compounds did not suppress appetite.

To investigate the antihyperlipidemic effect of RHA and RHG, the serum lipid level was measured in HCD-induced hyperlipidemic rats after treatment. The TC and LDL-C levels in HCD-fed rats increased 2.0- and 5.8-fold, respectively, compared with the watertreated control; however, the serum lipid level decreased in HCD-fed rats treated with RHA or RHG dose-dependently, indicating the efficacy of RHA and RHG in preventing the elevation of the serum lipid level under experimentally-induced hyperlipidemia ( $\odot$ Table 2). Although there was a slight increase in the HDL-C level in HCD-fed rats treated with RHG, the significant difference in the HDL-C level was not shown after RHG treatment. The serum TC level was significantly $(\mathrm{p}<0.05)$ lower in HCD-fed rats treated with RHG than that in the HCD-fed control. The serum TC levels in HCD-fed rats treated with RHA or RHG at $5 \mathrm{mg} /$ $\mathrm{kg} /$ day were reduced by $21.0 \%$ and $33.6 \%$, respectively, compared with the HCD-fed control. Furthermore, although there was an increase in the HDL-C level in HCD-fed rats treated with RHG at
$5 \mathrm{mg} / \mathrm{kg} /$ day, the serum lipid level was similar to that of the HCD-fed rats treated with simvastatin at $1 \mathrm{mg} / \mathrm{kg} /$ day. High levels of LDL-C, TC, and VLDL-C contribute to the development of cardiovascular disease. In the present study, although the HDL-C level in HCD-fed rats treated with RHG increased slightly, there was no significant change in the HDL-C level in all HCD-fed rats. This observation indicates that methoxylated stilbenes, particularly RHG, may possess cardioprotective potential. The results from serum lipid analysis in HCD-fed rats treated with methoxylated stilbenes indicate that the RHG aglycone was more effective than its glycosylated RHA counterpart in the reduction of serum lipid levels.

The oral administration of rhaponticin (rhapontin) $(125 \mathrm{mg} / \mathrm{kg}$ ) from rhubarb rhizomes reduced the serum lipid level in KK/Ay diabetic mice [18]. Compared to the previous report, the oral administration of remarkably low concentrations of rhapontin (2.5 and $5 \mathrm{mg} / \mathrm{kg}$ ) from $R$. undulatum showed a hypolipidemic effect in HCD-fed rats. A polyphenolic stilbenoid, resveratrol, shows beneficial effects on the prevention of dyslipidemia by activating cholesterol $7 \alpha$-hydroxylase and increasing the bile acid pool size [19]. Furthermore, pterostilbene (3,5-dimethoxy-4'-hydroxystilbene) lowers serum lipoprotein and cholesterol levels in hypercholesterolemic hamsters by acting as a peroxisome proliferator-activated receptor $\alpha$ (PPAR $\alpha$ ) that plays a central role in lipid homeostasis [20]. Pterostilbene also shows a higher hypolipidemic effect than resveratrol. RHA and RHG showed inhibitory activities against 3-hydroxy-3-methylglutaryl coenzyme A (HMG-CoA) reductase and squalene synthase, which are key enzymes in the cholesterol biosynthesis pathway [21]. In addition, although RHG, a methoxylated stilbene aglycone, contains more hydroxyl groups and one less methoxyl group than pterostilbene, it may show the same antihyperlipidemic mechanism. Further 
Table 2 Effect of the high-cholesterol diet and simvastatin, rhapontin, or rhapontigenin treatment on the serum lipid level in rats.

\begin{tabular}{|c|c|c|c|c|c|c|c|}
\hline \multirow{2}{*}{$\begin{array}{l}\text { Treatment } \\
\text { group }\end{array}$} & \multicolumn{2}{|l|}{$\mathrm{U} / \mathrm{L}$} & \multicolumn{5}{|l|}{ Levels (mg/dL) } \\
\hline & AST & ALT & TC & HDL & LDL & VLDL & TG \\
\hline I & $86.7 \pm 11.0$ & $40.5 \pm 8.1$ & $75.8 \pm 10.5^{a}$ & $40.8 \pm 4.8^{b}$ & $19.3 \pm 3.4^{\mathrm{a}}$ & $15.7 \pm 2.6^{e}$ & $78.4 \pm 13.0^{\mathrm{e}}$ \\
\hline II & $92.5 \pm 7.0$ & $39.3 \pm 4.3$ & $154.8 \pm 18.6^{c}$ & $28.6 \pm 4.8^{a}$ & $112.1 \pm 22.8^{\mathrm{d}}$ & $14.1 \pm 2.2^{\mathrm{d}, \mathrm{e}}$ & $70.5 \pm 10.9^{d, e}$ \\
\hline III & $101.3 \pm 21.1$ & $40.3 \pm 3.8$ & $99.3 \pm 28.7^{\mathrm{a}, \mathrm{b}}$ & $26.5 \pm 2.9^{a}$ & $61.8 \pm 26.3^{b}$ & $11.0 \pm 1.5^{b, c}$ & $54.8 \pm 9.6^{a, b, c}$ \\
\hline IV & $90.4 \pm 6.8$ & $42.5 \pm 4.3$ & $161.5 \pm 39.9^{c}$ & $31.8 \pm 3.6^{a}$ & $102.0 \pm 29.1^{c, d}$ & $15.4 \pm 1.4^{e}$ & $76.8 \pm 7.2^{\mathrm{e}}$ \\
\hline V & $88.2 \pm 12.4$ & $38.0 \pm 6.9$ & $131.8 \pm 8.0^{\mathrm{b}, \mathrm{c}}$ & $30.5 \pm 6.9^{a}$ & $86.0 \pm 16.5^{b, c, d}$ & $12.8 \pm 1.0^{c, d}$ & $64.0 \pm 5.1^{c, d}$ \\
\hline $\mathrm{VI}$ & $85.8 \pm 6.1$ & $35.2 \pm 3.6$ & $122.3 \pm 33.2^{b}$ & $27.7 \pm 4.7^{a}$ & $73.8 \pm 26.3^{b, c}$ & $12.0 \pm 2.4^{b, c, d}$ & $59.8 \pm 11.8^{\mathrm{c}, \mathrm{d}, \mathrm{e}}$ \\
\hline VII & $84.5 \pm 6.9$ & $41.2 \pm 1.5$ & $115.3 \pm 24.9^{b}$ & $30.5 \pm 4.7^{a}$ & $74.8 \pm 23.6^{\mathrm{b}, \mathrm{c}}$ & $10.1 \pm 1.2^{\mathrm{a}, \mathrm{b}}$ & $50.3 \pm 5.8^{a, b}$ \\
\hline VIII & $87.8 \pm 7.0$ & $39.5 \pm 4.2$ & $114.0 \pm 25.2^{b}$ & $30.2 \pm 5.1^{a}$ & $68.0 \pm 23.4^{b}$ & $10.1 \pm 1.9^{\mathrm{a}, \mathrm{b}}$ & $50.3 \pm 9.5^{a, b}$ \\
\hline IX & $89.0 \pm 14.1$ & $38.3 \pm 5.3$ & $102.8 \pm 14.5^{a, b}$ & $33.7 \pm 8.1^{\mathrm{a}}$ & $60.4 \pm 12.5^{b}$ & $8.8 \pm 1.9^{a}$ & $44.0 \pm 9.5^{a}$ \\
\hline
\end{tabular}

Group I, normal diet + $10 \mathrm{~mL} / \mathrm{kg} /$ day distilled water; group II, HCD; group III, HCD + 1 mg/kg/day simvastatin; group IV, HCD + 1 mg/kg/day RHA; group V, HCD + $2.5 \mathrm{mg} / \mathrm{kg} /$ day RHA; group VI, HCD + 5 mg/kg/day RHA; group VII, HCD + 1 mg/kg/day RHG; group VIII, HCD + $2.5 \mathrm{mg} / \mathrm{kg} /$ day RHC; and group IX, HCD + $5 \mathrm{mg} / \mathrm{kg} /$ day RHG; a, b, c, d, e Means in the same column not sharing a common superscript are significantly $(p<0.05)$ different between groups
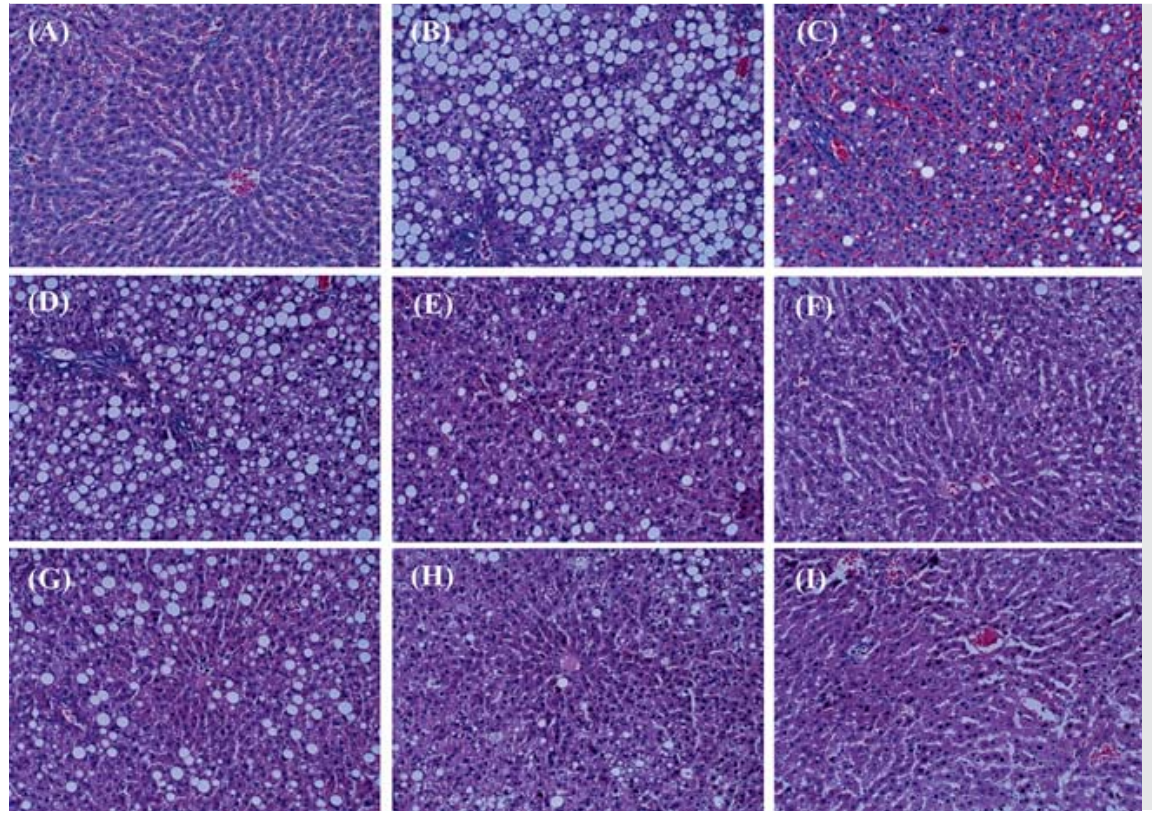

Fig. 2 Histological analysis of the liver from hyperlipidemic rats who were fed a high-cholesterol diet and treated with rhapontin or rhapontigenin. A normal diet; B HCD; C HCD + $1 \mathrm{mg} / \mathrm{kg} /$ day simvastatin; $\mathbf{D} \mathrm{HCD}+1 \mathrm{mg} / \mathrm{kg} /$ day RHA; $\mathbf{E} \mathrm{HCD}+$ $2.5 \mathrm{mg} / \mathrm{kg} /$ day RHA; $\mathbf{F}$ HCD $+5 \mathrm{mg} / \mathrm{kg} /$ day RHA; G HCD $+1 \mathrm{mg} / \mathrm{kg} /$ day RHG; $\mathbf{H}$ HCD $+2.5 \mathrm{mg} / \mathrm{kg} /$ day RHG; I HCD $+5 \mathrm{mg} / \mathrm{kg} /$ day RHG. All images are shown at 200× magnification. (Color figure available online only.) studies are needed to clarify the mechanism of action of RHG on antihyperlipidemia.

The liver from HCD-fed rats treated with RHA or RHG was examined for histopathological changes. Liver cells from HCD-fed rats were altered compared with those of rats fed a normal diet, which did not show abnormal morphology ( $\bullet$ Fig. 2). Numerous lipid droplets were observed in the cytoplasm of centrilobular hepatocytes in livers from HCD-fed rats compared with those from rats fed a normal diet ( Fig. $2 \mathbf{A}$ and $\mathbf{B}$ ). By contrast, the number of lipid droplets significantly decreased in HCD-fed rats treated with simvastatin ( $\bullet$ Fig. 1C), RHA, or RHG, dose-dependently ( Fig. 2D-I). Lipid droplets in liver cells from HCD-fed rats treated with RHA or RHG at $5 \mathrm{mg} / \mathrm{kg} /$ day were hardly observed ( $\bullet$ Fig. $2 \mathrm{~F}$ and $\mathbf{I}$ ). The results indicate that methoxylated stilbenes, especially RHG, can reverse HCD-induced liver cell degeneration.

In conclusion, RHA and RHG treatment lowered the serum lipid level dose-dependently and reversed hyperlipidemia in HCD-fed rats. A histological study also showed that RHA and RHG decreased the number of lipid droplets in liver cells from HCD-fed rats, consistent with the serum lipid analysis results. RHG showed a higher preventive effect against hyperlipidemia than RHA, illustrating that the aglycone was more effective to reduce the risk for hyperlipidemia than the glycosylated counterpart.

\section{Materials and Methods \\ $\nabla$ \\ Chemicals}

RHA (3,3',5-trihydroxy-4'-methoxystilbene-3-0-glucoside) was isolated from a methanol extract of Rheum undulatum roots, and RHG (3,3',5-trihydroxy-4'-methoxystilbene) was produced from RHA via an enzymatic transformation using Pectinex ${ }^{\circledR}$ (Novozymes) as previously described [17]. The purity of RHA and RHG was over $95 \%$. Simvastatin (purity $\geq 97 \%$ ) and DMSO were purchased from Sigma Chemical Co. 


\section{Experimental animals and diets}

Sprague Dawley rats $(n=54)$, five weeks old and weighing approximately $100-110 \mathrm{~g}$, were purchased from Koatech. They received a normal diet for one week to allow for adaptation. Rats were housed in cages under strict standard conditions $\left(22 \pm 1^{\circ} \mathrm{C}\right.$; $55 \pm 5 \%$ humidity; 12 -h light and 12 -h dark cycles). The animals had free access to water and a normal diet or an experimental HCD purchased from Feedlab. The composition of diets is shown in Table 1S, Supporting Information. All experimental procedures were approved by the Korea University Institutional Animal Care and Use Committee (approval No. KUIACUC-2012-100) and were followed according to the Guide for the Care and Use of Laboratory Animals (NIH publication No. 85-23, 1996).

\section{Induction of hyperlipidemia with}

\section{a high-cholesterol diet}

After adaptation, rats were randomly divided into nine groups, with each group consisting of six rats. RHA or RHG was orally administrated to rats daily for four weeks. Animals in group I (negative control) were fed a normal diet and orally treated with distilled water at $10 \mathrm{~mL} / \mathrm{kg} / \mathrm{day}$ for four weeks. Animals in group II (experimental control) were fed the HCD instead of the normal diet (Table 1S, Supporting Information). Animals in group III (positive control) were fed the HCD and orally treated with simvastatin at $1 \mathrm{mg} / \mathrm{kg} /$ day in $10 \mathrm{~mL} / \mathrm{kg}$ DMSO and distilled water $(1: 9, \mathrm{v} / \mathrm{v})$ for four weeks. Animals in groups IV, V, and VI were fed the HCD and orally treated with RHA at $1,2.5$, and $5 \mathrm{mg} / \mathrm{kg} /$ day in $10 \mathrm{~mL} / \mathrm{kg}$ DMSO and distilled water $(1: 9, \mathrm{v} / \mathrm{v})$, respectively. Animals in groups VII, VIII, and IX were fed the HCD and orally treated with RHG at $1,2.5$, and $5 \mathrm{mg} / \mathrm{kg} /$ day in $10 \mathrm{~mL} / \mathrm{kg}$ DMSO and distilled water $(1: 9, \mathrm{v} / \mathrm{v})$, respectively.

\section{Measurement of daily food intake, body weight, and relative liver weight}

Daily food intake was assessed by subtracting the weight of any leftover food from the weight of the total amount of food provided, divided by six for each group. The body weight of each rat was obtained weekly. The absolute liver weight was obtained, and the relative liver weight per $100 \mathrm{~g}$ of total body weight was calculated as follows:

Rel. liver weight $=\frac{\text { weight of rat liver }(\mathrm{g})}{\text { body weight of the final experimental day }(\mathrm{g})} \times 100$

\section{Blood collection and biochemical assays}

After treatment for four weeks, blood was collected from the heart of overnight fasted rats under diethyl ether anesthesia and allowed to clot at room temperature. Sera were obtained by centrifugation at $10000 \times \mathrm{g}$ at $4^{\circ} \mathrm{C}$ for $20 \mathrm{~min}$. Serum TG, TC, HDL-C, AST, and ALT levels were measured using the FUSI DRI-CHEM SLIDE kit and a FUSI DRI-CHEM 4000 analyzer (Fujifilm). The serum LDL-C level was calculated by applying Frieldwann's equation:

LDL-C $=\left[\mathrm{TC}-\left(\mathrm{HDL}-\mathrm{C}+\left(\frac{\mathrm{TG}}{5}\right)\right]\right.$

The serum VLDL-C level was calculated by applying the following equation:

VLDL-C $=\frac{T G}{5}$

\section{Hepatic morphology}

For histological analysis, liver specimens were fixed in $10 \%$ formalin and embedded in paraffin. Paraffin blocks were cut at $5 \mu \mathrm{m}$, and sections were stained with hematoxylin and eosin and then mounted with Canada balsam. The slides were observed under an optical microscope at 200× magnification [22].

\section{Statistical analysis}

All data are presented as means \pm standard error. The data were analyzed using the SPSS statistical analysis program. Significant differences between groups were determined by one-way analysis of variance. Post hoc Duncan's multiple-range tests were performed when between-group differences were identified. Results were considered to be statistically significant at $\mathrm{p}<0.05$.

\section{Supporting information}

Details about the composition of the experimental diets are available as Supporting Information.

\section{Acknowledgments \\ $\nabla$}

This research was supported by the High Value-added Food Technology Development Program, Ministry of Agriculture, Food and Rural Affairs, Republic of Korea.

\section{Conflict of Interest}

$\nabla$

The authors declare no conflict of interest.

\section{References}

1 Sharma RK, Singh VN, Reddy HK. Thinking beyond low-density lipoprotein cholesterol: strategies to further reduce cardiovascular risk. Vasc Health Risk Manag 2009; 5: 793-799

2 Berrougui H, Momo CN, Khalil A. Health benefits of high-density lipoproteins in preventing cardiovascular diseases. J Clin Lipidol 2012; 6: 524-533

3 Barter $P$. The role of HDL-cholesterol in preventing atherosclerotic disease. Eur Heart J Suppl 2005; 7: F4-F8

4 Sewright KA, Clarkson PM, Thompson PD. Statin myopathy: incidence, risk factors, and pathophysiology. Curr Atheroscler Rep 2007; 9: 389396

5 Beltowski J, Wojcicka G, Jamroz-Wisniewska A. Adverse effects of statins - mechanisms and consequences. Curr Drug Saf 2009; 4: 209-228

6 Whitlock NC, Baek SJ. The anticancer effects of resveratrol: modulation of transcription factors. Nutr Cancer 2012; 64: 493-502

7 Santos JA, de Carvaho GS, Oliveira V, Raposo NR, da Silva AD. Resveratrol and analogues: a review of antioxidant activity and applications to human health. Recent Pat Food Nutr Agric 2013; 5: 144-153

8 Chung KO, Kim BY, Lee MH, Kim YR, Chung HY, ParkJH, Moon JO. In-vitro and in-vivo anti-inflammatory effect of oxyresveratrol from Morus alba L. J Pharm Pharmacol 2003; 55: 1695-1700

9 Hasiah A, Ghazali A, Weber J, Velu S, Thomas N, Inayat Hussain S. Cytotoxic and antioxidant effects of methoxylated stilbene analogues on HepG2 hepatoma and Chang liver cells: Implications for structure activity relationship. Hum Exp Toxicol 2011; 30: 138-144

10 Wilson MA, Rimando AM, Wolkow CA. Methoxylation enhances stilbene bioactivity in Caenorhabditis elegans. BMC Pharmacol 2008; 8: 15

11 Roupe KA, Remsberg CM, Yanez JA, Davies NM. Pharmacometrics of stilbenes: seguing towards the clinic. Curr Clin Pharmacol 2006; 1: 81101

12 Roupe KA, Helms GL, Halls SC, Yanez JA, Davies NM. Preparative enzymatic synthesis and HPLC analysis of rhapontigenin: applications to metabolism, pharmacokinetics and anti-cancer studies. J Pharm Pharm Sci 2005; 8: 374-386

13 Zhang R, Kang KA, Piao MJ, Lee KH, Jang HS, Park MJ, Kim BJ, Kim JS, Kim YS, Ryu SY, Hyun JW. Rhapontigenin from Rheum undulatum protects 
against oxidative-stress-induced cell damage through antioxidant activity. J Toxicol Environ Health A 2007; 70: 1155-1166

14 Park EK, Choo MK, Yoon HK, Kim DH. Antithrombotic and antiallergic activities of rhaponticin from Rhei Rhizoma are activated by human intestinal bacteria. Arch Pharm Res 2002; 25: 528-533

15 Lee J, Kim JM, Kim C. Pharmacokinetic analysis of rhein in Rheum undulatum L. J Ethnopharmacol 2003; 84: 5-9

16 Matsuda H, Morikawa T, Toguchida I, Park J, Harima S, Yoshikawa M. Antioxidant constituents from rhubarb: structural requirements of stilbenes for the activity and structures of two new anthraquinone glucosides. Bioorg Med Chem 2001; 9: 41-50

$17 \mathrm{Kim} \mathrm{JK}, \mathrm{Kim} \mathrm{N}$, Lim YH. Evaluation of the antibacterial activity of rhapontigenin produced from rhapontin by biotransformation against Propionibacterium acnes. J Microbiol Biotechnol 2010; 20: 82-87

18 Chen J, Ma M, Lu Y, Wang L, Wu C, Duan H. Rhaponticin from rhubarb rhizomes alleviates liver steatosis and improves blood glucose and lipid profiles in KK/Ay diabetic mice. Planta Med 2009; 75: 472-477
19 Chen $Q$ Wang E, Ma L, Zhai P. Dietary resveratrol increases the expression of hepatic 7alpha-hydroxylase and ameliorates hypercholesterolemia in high-fat fed C57BL/6J mice. Lipids Health Dis 2012; 11: 56

20 Rimando AM, Nagmani R, Feller DR, Yokoyama W. Pterostilbene, a new agonist for the peroxisome proliferator-activated receptor alpha-isoform, lowers plasma lipoproteins and cholesterol in hypercholesterolemic hamsters. J Agric Food Chem 2005; 53: 3403-3407

21 Park K, Kim J, Lim Y. Deglycosylation of stilbene glucoside compounds improves inhibition of 3-hydroxy-3-methylglutaryl coenzyme a reductase and squalene synthase activities. Food Sci Biotechnol 2014; 23: 647-651

$22 \mathrm{Hsu} C \mathrm{CL}, \mathrm{Wu} \mathrm{CH}$, Huang SL, Yen GC. Phenolic compounds rutin and ocoumaric acid ameliorate obesity induced by high-fat diet in rats. J Agric Food Chem 2009; 57: 425-431 